Revista de la red interuniversitaria de estudios sobre las literaturas rioplatenses contemporáneas en Francia

8 | 2013

Argentina y Uruguay: lecturas del país vecino en la literatura rioplatense contemporánea (siglos XX y XXI)

\title{
Escribir en la orilla. Encuesta a escritores actuales de ambos lados del Río de la Plata
}

Valentina Litvan

\section{OpenEdition}

1 Journals

Edición electrónica

URL: http://journals.openedition.org/lirico/1021

DOI: $10.4000 /$ lirico.1021

ISSN: 2262-8339

Editor

Réseau interuniversitaire d'étude des littératures contemporaines du Río de la Plata

Referencia electrónica

Valentina Litvan, « Escribir en la orilla. Encuesta a escritores actuales de ambos lados del Río de la Plata », Cuadernos LIRICO [En línea], 8 | 2013, Puesto en línea el 01 enero 2013, consultado el 19 abril 2019. URL : http://journals.openedition.org/lirico/1021 ; DOI : 10.4000/lirico.1021

Este documento fue generado automáticamente el 19 abril 2019.

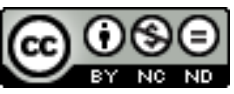

Cuadernos LIRICO está distribuido bajo una Licencia Creative Commons Atribución-NoComercialSinDerivar 4.0 Internacional. 


\title{
Escribir en la orilla. Encuesta a escritores actuales de ambos lados del Río de la Plata
}

\author{
Valentina Litvan
}

1 Las fronteras entre Argentina y Uruguay han sido desde sus inicios culturalmente imprecisas : baste la gauchesca para atestiguar del origen literario compartido por el vasto territorio cuya denominación da el Río de la Plata. Los viajeros entre un país y otro abundaron en el siglo XIX, construyendo un imaginario móvil, fluctuante. Bartolomé Hidalgo o Acuña de Figueroa contribuyen a la creación de ese espacio previo al Estado nación. Cuando más tarde W. H. Hudson describe la fauna y la flora rioplatenses, no necesita establecer la diferencia entre los dos países. La realidad de ambos lados del Plata fue descrita por muchos escritores con la mirada inquieta no sólo del viajero extranjero que la observa con interés científico, sino del propio habitante que por tener que pasar de un lado a otro del río acaba, de algún modo, perteneciendo a ambas orillas, o cuanto menos apropiándoselas. Horacio Quiroga es un caso emblemático del escritor fronterizo.

Distintos autores argentinos imaginaron la realidad de su país desde el Uruguay, participando en una construcción de literatura nacional paradójicamente desde afuera. El exilio oriental unió por ejemplo a Juan Bautista Alberdi y Esteban Echeverría en las diatribas contra el régimen rosista. La distancia tuvo que influir en la mirada hacia la realidad de su país y en la libertad que tenían al analizarla, describirla y recrearla en sus textos. También desde el Uruguay, José Mármol escribió por los años 1840 Amalia, novela considerada fundacional de la literatura argentina.

El viaje científico, el exilio político o los diálogos intelectuales siguieron siendo motivo de vaivenes entre las dos bandas del Río de la Plata en el s. XX, enriqueciendo las zonas de intercambio que exceden los aspectos estrictamente formales de la categoría de nación. Experiencias que proceden de viajes reales, pero también un imaginario rioplatense transmitido a través de los textos, heredado a veces exclusivamente mediante la lectura.

4 Se trata de la escritura de -o desde- un país que es otro, el de enfrente, y que a la vez se reconoce como familiar, el país vecino cuyo límite es un río al que ambos consideran 
como propio y que sin embargo los separa. Un « río sin orillas» que a medida que se adentra en el interior, permite que haya, en palabras de Juan José Saer, «más puntos comunes entre el Uruguay y el litoral argentino, que entre ese mismo litoral y el resto de la república ». Un río que desde el otro extremo, en cambio, enfrentando los dos puertos, pone de espaldas a dos capitales imposibles de divisarse la una a la otra desde sus muelles respectivos; un río que se confunde entonces con el mar. Un río que se cruza a diario comunicando ambos puertos pero que también fue pozo insondable e incomprensible durante la última dictadura, haciendo de los muertos un destino común sin asidero. Escenario de dramas reales, contenedor de batallas arcaicas y de secretos infames, también fue y seguirá siendo el símbolo que se impone entre un país y otro, posibilidad de creación y de esperanza en el lenguaje y la comunicación. Un río, que como recuerda Fernanda Trías, fue descrito por Arlt como « extensión de tierra pisoteada por caballos ", perdiendo así la propiedad acuosa de todo río y dejando por lo tanto de existir como tal. Un río que sin embargo renace de sí mismo para acercar -o alejar- los dos países cuyas orillas lo configuran.

5 La distancia relativa entre un país y otro es la que se pretende interrogar con esta encuesta a escritores actuales de ambas orillas del Plata. Las posiciones varían, desde la evocación nostálgica con ecos borgeanos que perdura en autores como Hernán Ronsino, quien a pesar de confesar no haber viajado nunca a Uruguay -o precisamente por eso mismo- lo imagina a partir del mito, como una Buenos Aires del pasado. Borges escribía de Montevideo: «Eres el Buenos Aires que tuvimos, el que en los años se alejó quietamente / [ ...] Puerta falsa en el tiempo.» Y es porque no hace falta haber viajado al Uruguay para pensarlo que Sergio Chejfec puede afirmar : «El Uruguay es una deriva, el sueño preservado de la Argentina imposible. » $O$ decir incluso que el Uruguay es « una especie de parque temático de la ficción argentina », con resultados cada vez más pobres. Pero frente a esa actitud nostálgica en la que la Banda Oriental se convierte en una construcción simbólica, encontramos la presencia ambivalente fruto de la experiencia de quien ha vivido -y en ocasiones ha escrito- en ambos países. Es tal vez el extrañamiento la posición privilegiada para contar lo otro de uno mismo. Así, Alicia Migdal se siente parte integrante de Argentina pero inevitablemente extranjera o, como en un «juego de espejos », Carlos María Domínguez se reconoce " con una doble pertenencia y una doble extranjería ». En el caso de la uruguaya Fernanda Trías, nómade desde hace algunos años, expresa la necesidad de publicar sus libros en las ciudades donde vive para poder habitarlas cabalmente. Y para Juan Carlos Mondragón, hablar de literatura rioplatense es, simple y llanamente, una cuestión de fe.

\section{Carlos María Domínguez}

\section{1) ¿Qué le evoca el Río de la Plata ?Qué representa para usted, en su imaginario literario ?}

Viví mi infancia y juventud en el barrio de olivos, a pocas cuadras de la costa, cuando sus balnearios todavía reunían una fiesta popular en los veranos, la troupe de Martín Karadagián entrenaba en las barras y trapecios de la playa, había kermeses y una colorida fauna de personajes bajaba de los camiones que llegaban de todas partes de la ciudad, con sus termos y radios y abuelas y perros, bajo la mirada aprehensiva de los que iban a los clubs, porque el río se llenaba de « cabecitas negras ».

En el puerto de yates de Olivos estaba la prefectura, que no molestaba, y había grandes cajoneras de arena que las dragas volcaban con gruesos mangones, donde podíamos 
jugar y una vez estuve a punto de romperme el cuello. Muchos pescadores ocupaban el muelle que entraba en el río, coronado por un faro sobre una casilla de puertas y ventanas desgonzadas, orines, grafitis y restos de pescado, con una escalera a la que se podía subir para ver el río como desde la baranda de un barco.

Las ratas a la escuela (no sé por qué le decíamos « hacerse la rata » a faltar a la escuela sin permiso) incluía la aventura de caminar varios kilómetros por las vías abandonadas del ferrocarril Mitre, que se pegaba a la costa hasta Tigre y era refugio de muchos linyeras con los que a menudo nos deteníamos a conversar y a oír sus historias. En La Lucila había casillas de pescadores artesanales, levantadas sobre pilotes para enfrentar las crecientes, y se extendían junto a las vías del tren hasta San Isidro. En las noches de verano, después de los bailes, solía ir con mis amigos a la playa del YCO (Yacht Club de Olivos), nos echábamos en la arena a fumar y a imaginar nuestros destinos. El río era el único espacio que ofrecía un horizonte abierto donde perder la vista, y lo asociábamos a la libertad. La libertad de llevar la mirada hacia donde quisiéramos, del bikini que tomaba sol a nuestro lado al barco que cruzaba a lo lejos, y de vivir al margen de las obligaciones que nos imponía la ciudad.

Con todo eso acabó la dictadura militar, que cerró los balnearios y los cubrió de escombros provenientes de la construcción de las autopistas. Las industrias contaminaron las aguas y los baños quedaron prohibidos. Durante muchos años encontré pasadizos entre los tejidos de alambre para llegar a la orilla y pasar unas horas arrojando piedras al agua. La vida se había malogrado y el río también. $Y$ ahí estaba yo entre restos de ladrillos y plásticos, y toda clase de basuras, enseñándole a mi pequeño hijo a hacer sapitos sobre las olas.

Antes que un imaginario literario el río fue para mí una experiencia y una conversación. Pero entonces, como muchos porteños, creía conocerlo. «El gran río color de león » lo llamó Lugones. «El río inmóvil » dijo Mallea. «Río de sueñera y barro » corrigió Borges. Pero todavía me faltaba la otra orilla.

2) ¿Cuál es su relación biográfica con el país vecino ? (¿con qué frecuencia, a dónde va y por qué motivos viaja al otro lado del Río ?)

A inicios de los años setenta muchos uruguayos llegaron a Buenos Aires escapando del hambre o de la policía, después del golpe militar de junio del 73. Yo me estrenaba como periodista en la revista Crisis, que dirigía Eduardo Galeano, y ahí conocí a varios periodistas y escritores montevideanos como María Esther Gilio, Ernesto González Bermejo, Julio César Castro, entre otros. También conocí a un grupo de uruguayos desterrados, me casé con una exiliada que pertenecía a ese grupo, tuvimos un hijo. Cuando acabó la dictadura monté la segunda etapa de Crisis con Vicente Zito Lema y Osvaldo Soriano, a la que poco después se sumó Jorge Boccanera (ambos compartíamos la secretaría de redacción). Luego fui director de la tercera etapa de la revista y cuando nos peleamos con el dueño y quedé sin trabajo, me lo ofrecieron en el semanario Brecha, de Montevideo, del que era corresponsal en Buenos Aires. Entonces Carlos Menem acababa de subir al gobierno, sentí que la Argentina me expulsaba con sus abrazos al nuevo mesías, su impiedad social, su vertiginoso impudor. Junté mis libros y muebles a un camión, y crucé con mi familia la frontera por Gualeguaychú el día en que Menem indultó a los militares.

Desde octubre de 1989 vivo en Montevideo, hace ya 23 años. Acá fui jefe de redacción de Brecha, editor de las páginas literarias del semanario Búsqueda, y desde que lo inició Homero Alsina Thevenet, colaboro con el suplemento Cultural del diario El País. Durante 
muchos años fui «el porteño» en Montevideo, y «el uruguayo » en Buenos Aires. Ahora ya no me dicen "porteño » porque pasaron muchos años y aunque sigo siendo argentino, me convertí en uruguayo por adopción. No es un trámite. Es otra experiencia, literaria también, porque cuando me radiqué en Montevideo había publicado en Emecé mi primera novela, Pozo de Vargas, y me mudaba en mitad de otra, La mujer hablada ; pero el resto de mi obra ha sido escrita en Uruguay.

Ahora regreso a Buenos Aires dos o tres veces al año, para ver a mi familia y a mis amigos, y me siento más extranjero que en Montevideo. El Río de la Plata es para mí un juego de espejos que atravieso con una doble pertenencia y una doble extranjería. A veces lo agradezco, y a veces no.

3) ¿Ha escrito en la otra orilla? ¿Influye la distancia en su escritura?

Escribí en Uruguay una veintena de libros, entre novelas, cuentos, biografías, crónicas de viaje, investigaciones. En su mayoría son historias que cruzan las dos orillas en distintas épocas, como mi biografía de Juan Carlos Onetti, la del poeta y dandy Roberto de las Carreras, hijo de una cadena de escándalos del patriciado argentino a fines del siglo XIX, la del pintor Tola Invernizzi, o mis crónicas de la costa y la navegación en el Río de la Plata.

Desde que llegué a Montevideo la distancia se convirtió en decisiva, acaso estuvo desde el inicio porque un escritor vive de esa distancia interior, pero acá se expandió hacia zonas de la imaginación que en Buenos Aires estaban cerradas y se volvió más potente a la hora de mirar la vida argentina desde una orilla falsamente gemela -es notoria la teatralidad de sus episodios políticos y la velocidad con que Argentina naturaliza sus miserias-, y sobre todo a la hora de contemplar la vida uruguaya, dueña de otro modo de habitar el tiempo. Ya lo había avisado Borges en un poema de Cuadernos San Martín, Montevideo es una falsa puerta en el tiempo, y lo que muchas veces he creído comprobar es que se organiza sobre la discreción, la melancolía y la decisión de un país que no aspira a ser otra cosa que lo que ya es, asunto que cumple con sus virtudes y sus tormentos.

La distancia me permitió conocer también, que «el gran río color de león » tiene en verdad tres colores, el que le encontró Lugones cuando descarga el Paraná, agrisado y pardo cuando lo hace el Uruguay, que arrastra tierras negras, y azul cuando el mar entra al estuario ; que « el río inmóvil » descarga 20 mil metros cúbicos por segundo y es el tercero más caudaloso del planeta, y que el río « de sueñera y barro » es un molino de corrientes trabadas que todo el tiempo mueve los fondos de lugar y por su sedimentación está condenado a desaparecer. Se rió Juan José Saer de que una bajante impidiera entrar al barco en el que viajaba a Montevideo, y me reconoció cordialmente en un mail personal que es precisamente su poco calado lo que produce el terror de los capitanes, que conocen el río como «el infierno de los navegantes». Son miles los cascos hundidos en el Río de la Plata, sin contar los cuerpos de los desaparecidos arrojados durante la dictadura militar. Y digo esto para recordar que no se conoce el Río de la Plata por su orilla argentina, como no lo conocía yo desde las playas de Olivos. Del lado oriental sobrevive una cultura de la costa que hace mucho no existe en la otra orilla. Una raza de pescadores, cazadores de pájaros, contrabandistas y piratas que viven en las cercanías del delta, al margen de otras leyes que no sean las de la fuerza y el coraje para sobrevivir. Conversé con muchos de ellos y navegué el Río de la Plata en canoa, en velero, en barcos portacontenedores, asombrado de sus extrañas paradojas, en su mayoría desconocidas para los habitantes de las ciudades que crecen en sus 
costas, quizá porque desde su origen de fortines, las épicas que alimentaron sus fantasías provenían de los terrores de la pampa y sus indios.

4) ¿Ha publicado o se ha planteado publicar en el país vecino ? ¿Por qué ?

Muchos de mis libros fueron publicados en Montevideo y Buenos Aires por Alfaguara y Mondadori, y otros tuvieron ediciones nacionales en Arca, Banda Oriental, Trilce, Cal y Canto, pero la mayor recepción de mi obra, salvo La casa de papel y las novelas que le siguieron, traducidas a varias lenguas, es uruguaya.

\section{5) ¿Qué autores contemporáneos del país vecino mencionaría y por qué ?}

«El país vecino » es una expresión compleja para mí. Pero puedo decir que Buenos Aires desconoce novelas y cuentos particularmente relevantes de Tomás de Mattos, Mario Delgado Aparaín, Henry Trujillo, Hugo Burel, Carlos Liscano, Hugo Fontana, la poesía de Circe Maia, Elder Silva, Rafael Courtoisie, entre otros, y sólo un reducido círculo de lectores argentinos conoce autores importantes, fallecidos en los últimos años, como es el caso de las poetas Idea Vilariño y Marosa di Giorgio, o el narrador Mario Levrero, cuya mayor recepción se produjo hace poco, además de otros autores de la literatura uruguaya de escasa recepción en Argentina. Desde siempre, por motivos culturales y comerciales, a Montevideo llegan las ediciones más destacadas de Buenos Aires, y a Buenos Aires rara vez llega una edición uruguaya.

6) ¿Podemos hablar de una literatura rioplatense? ¿en qué sentido? (movimientos estéticos comunes, historia cultural compartida, etc.) ¿Cree que ha existido un vínculo mayor en otras épocas?

Los vínculos históricos del Río de la Plata están pautados por la competencia de los puertos de Montevideo y Buenos Aires, dentro de una cultura regional común, que desde los orígenes intercambia contrabandos, perseguidos, migraciones de valores y bienes culturales. Montevideo ha sido refugio tradicional de exiliados argentinos y Buenos Aires meca de muchos destinos orientales. Horacio Quiroga, Florencio Sánchez, Natalio Botana, Juan Carlos Onetti, en épocas más cercanas Mario Benedetti o Eduardo Galeano, son los escritores más notorios, entre los muchos que sumaron desde la orilla uruguaya, al intercambio de la literatura rioplatense. El tránsito inverso ha sido más escaso, fuera de visitas puntuales y relevantes, como la de Guillermo E. Hudson y $L a$ tierra purpúrea, o algunos cuentos de Jorge Luis Borges, admirado frecuentador de la Banda Oriental. Pueden agregarse la atención crítica de Jorge B. Rivera y Jorge Lafforgue, las frecuentes y fraternas visitas de Haroldo Conti y la radicación del escritor rosarino Elvio Gandolfo, unos años antes de que yo llegara, además del joven Manuel Soriano, hace poco. Pero los movimientos estéticos han sido similares, si tenemos en cuenta el romanticismo, el criollismo, el modernismo, la narrativa urbana, el realismo, incluso ciertas manifestaciones del género fantástico y la literatura policial, y no encuentran paralelo tensiones importantes como la de los grupos de Boedo y Florida en Buenos Aires, o las de la generación crítica del 45 en Uruguay. Todo eso habilita, creo yo, la pertinencia de una literatura rioplatense en estado de formación, defendida por un tono común cultivado sobre la elipsis criolla, que nos diferencia del uso del idioma en América Latina, el Caribe y España, y agraviada por una similar ignorancia del fundamento físico que reúne ambas orillas : el régimen natural y geográfico del Río de la Plata. Tenemos un mundo muy similar al delta del Mississippi, pero no tenemos un Mark Twain o un Faulkner.

Montevideo registra más vínculos con Buenos Aires que Buenos Aires con Montevideo, y acaso por eso la pertinencia de la literatura rioplatense tiene mayor densidad que en 
la otra orilla. Es una densidad que todavía no alcanza una conciencia crítica regional, acaso porque Buenos Aires vive de espaldas al río, demasiado ocupada con ella misma para permitirse averiguar que forma parte de una unidad mayor.

\section{Juan Carlos Mondragón}

1) ¿Qué le evoca el Río de la Plata? ¿Qué representa para usted, en su imaginario literario ?

Las playas de la infancia. Achilles, Ajax y Exeter enfrentados al acorazado de bolsillo Graf Spee. El cordobés Juan Eduardo Hohberg liderando la delantera de Peñarol. El Vapor de la Carrera. La melodía de « Canaro en París ».

Satisface las equivalencias simbólicas del río : las fuentes, las orillas, la desembocadura y el otro lado. Ahí están para mí, necesariamente, la nave Argos, los naufragios, el buque fantasma, la isla Avalon, Moby Dick y el canto de las Sirenas.

2) ¿Cuál es su relación biográfica con el país vecino ? ¿con qué frecuencia, a dónde va y por qué motivos viaja al otro lado del Río ?)

En el año 1950 mis padres fueron de luna de miel a Buenos Aires y después volvieron otras veces ; estoy seguro que esas fueron las semanas más felices de su vida juntos. En tiempos difíciles en la Banda Oriental yo marchaba un par de días para allá para cambiar de aire. Tenía unos tíos muy queridos que vivían en La Plata. Cada vez que aterrizo en Montevideo trato de hacerme una escapada en Buquebús y camino por la ciudad siguiendo los protocolos del viajero que huye.

3) ¿Ha escrito en la otra orilla ? ¿Influye la distancia en su escritura?

Hasta ahora nunca escribí en Argentina. No lo sé con certeza, quiero suponer que influye y para bien.

4) ¿Ha publicado o se ha planteado publicar en el país vecino ? ¿Por qué ?

Sí, me publicaron en Buenos Aires algunos títulos. En la historia de los escritores uruguayos hay una vertiente que pasa por ahí; supongo que por razones personales y editoriales : otro mercado, mayor concentración editorial, posibles resonancias críticas, punto de apoyo para alcanzar lectores en otras lenguas. Uno nunca decreta incorporarse a un catálogo, lo hacen las personas y las circunstancias. Yo tuve la suerte de conocer a varios editores de la vecina orilla, pero fue Alberto Díaz el que decidió publicarme, y en eso estamos.

5) ¿Qué autores contemporáneos del país vecino mencionaría y por qué?

Alejandro Paternain, que fue uno de mis profesores de literatura en el liceo, me aconsejó con entusiasmo que leyera las novelas de Leopoldo Marechal. Poco tiempo después Marechal llegó a Montevideo para dictar una conferencia a la que asistí; al final fui a verlo y le pedí que me firmara un ejemplar de Adán Buenosayres. Fue muy amable y esa es para mí una escena fundadora. Después, Juan José Saer porque cada libro es a la vez lo que se glosa y lo imborrable. Ello puede dar una idea para deducir desde dónde puedo estar leyendo la producción más reciente.

6) ¿Podemos hablar de una literatura rioplatense? ¿en qué sentido? (movimientos estéticos comunes, historia cultural compartida, etc.) ¿Cree que ha existido un vínculo mayor en otras épocas?

Es una cuestión de Fe. La noción « literatura rioplatense » es huidiza y más últimamente cuando la adopción de lo bizarro resulta preferible a otras respiraciones de escritura. 
Yo en todo caso creo. Es cierto lo de una historia cultural compartida con piqueteros ocasionales, también los avatares biográficos a lo Horacio Quiroga y editoriales. Por ejemplo, la publicación en 1950 de La vida breve me parece el esplendor novelesco de lo rioplatense -es la gran novela riolplatense- y el comienzo de una atonía. El Río de la Plata se nutría, antes, de producciones cruzadas que resultaban suficientes. Leguisamo en Palermo, D'Arienzo en el Hotel Carrasco. Había una producción circulando que se interrumpió con la industria del entretenimiento bien conocida ; luego, en el reparto, resultamos consumidores de otras culturas y los éxitos recientes de Mc Cartney y Lady Gaga en los estadios paradigmáticos, son ejemplares al respecto. Ahora el vínculo existe, pero intercambiamos bolitas y figuritas de los otros con una alegría desconcertante. De última está la decisión personal con menos verso. Lo que hacemos con el tiempo que nos queda, que me queda. No necesito leer a Philip K. Dick para conocer algún arcano hipotético del mundo, pero siempre que puedo escucho «La cachila», y la versión de Rodolfo Daluisio me alucina hasta la epifanía.

\section{Alicia Migdal}

1) ¿Qué le evoca el Río de la Plata ? ¿Qué representa para usted, en su imaginario literario ?

El espacio natural, el destino manifiesto, el habla cotidiana y el pensamiento obsesivo sobre semejanzas y diferencias.

2) ¿Cuál es su relación biográfica con el país vecino ? ¿con qué frecuencia, a dónde va y por qué motivos viaja al otro lado del Río ?)

Soy nieta de judíos de ambas vertientes. Venidos de Esmirna, mis abuelos maternos y todos sus hermanos se instalaron en Buenos Aires, donde nació mi madre. Pero al año se vinieron para Montevideo. Muchos familiares siguieron su vida en Argentina ; uno de ellos murió en el atentado a la AMIA. Cuando chica, Buenos Aires era para mí el lugar de las grandes familias y de los cuentos de mi madre, que pasó allí su luna de miel, una especie de fantaseado deseo de ampliación del horizonte. A mis catorce años nos fuimos y vivimos tres meses solamente, una experiencia rara que todavía hoy está presente, sobre todo por el olor de la nafta, que era distinto al de Montevideo y por los cambios posteriores que ese movimiento familiar generó. Y por la experiencia fundamental de extrañamiento, esa mezcla de futuro y ajenidad. Mi hijo y mis dos nietos viven en Buenos Aires. Pero hay dos ciudades para mí, la cotidiana de mi familia de hoy y la del pasado entresoñado.

En los 70 mis amigos me contaron que mi apellido estaba asociado a una organización de trata de judías polacas de los años 20, la Zwi Migdal, de gran alcance en Rosario y Buenos Aires. Hoy por hoy hay mucho material literario, teatral y periodístico sobre ellos, pero en aquel momento poco se sabía. Me produjo un gran sobresalto en ese tiempo leer en una de las novelas de Mario Szichman que uno de sus personajes se había topado con uno "de la Migdal». Yo leí con mucha dedicación la trilogía de Szichman de los 70, un autor que al no vivir en la Argentina parece haber quedado fuera del corpus.

3) ¿Ha escrito en la otra orilla ? ¿Influye la distancia en su escritura?

$\mathrm{He}$ escrito incluyendo a la otra orilla como pasado deseado y temido, sobre todo últimamente. Allí solo hago anotaciones en la libreta. Yo solo puedo escribir en mi casa. 
Pero ir y volver pone en movimiento memoria y deseo, para decirlo con palabras de Eliot. El pasado es siempre el verdadero viaje, o el verdadero viaje es siempre al pasado, así que en cuanto me subo al ómnibus, voy dejando las calles del Prado que son las que más amo, llego a Colonia y me tomo el buque, ya estoy en otro lado : un lugar mental. El movimiento crea la distancia y la distancia me acerca a ese lugar mental, donde se juega la literatura.

4) ¿Ha publicado o se ha planteado publicar en el país vecino ? ¿Por qué?

Sí, lo pensé por la evidente razón de que es un mercado amplio aunque por eso mismo despersonalizado. Pero en verdad una quiere ser leída y comprendida en su tierra, por algunas personas. La naturaleza de lo que escribo me delata, por lo tanto difícilmente yo haga movimientos de promoción de mi literatura. (Cuando en París editaron una de mis nouvelles fue a iniciativa del traductor, un estudiante que estaba trabajando ese texto). Creo que los editores argentinos se interesan mayoritariamente por nuestras rarezas literarias, o mejor dicho por la idea que ellos tienen de provocación e innovación, que por otra parte está muy bien representada por varios escritores uruguayos de peso, como Levrero, Marosa, Echavarren.

5) ¿Qué autores contemporáneos del país vecino mencionaría y por qué ?

Rodolfo Walsh será siempre un contemporáneo. Esa elegancia narrativa, esas elipsis. Su periodismo de investigación, tan unido a su inicial literatura policial de «formato enigma " y a sus traducciones de los norteamericanos. Lo amé instantáneamente por sus cuentos irlandeses, que atesoro. Después vino su fusilamiento. Pablo Ramos, que tiene un dominio del relato y un mundo oscuro expuesto con estrategias de claridad que me resulta altamente atractivo y temible. Ricardo Piglia, por las afinidades culturales y literarias. Washington Cucurto, que ha hecho literatura con aquello que supuestamente no se puede poetizar, algo no imaginable en la literatura uruguaya. Patricia Suárez y su saga teatral sobre nazis en Argentina.

Lo que me resulta más fuertemente definitorio de la literatura argentina actual y que no identifico en la nuestra es el proyecto literario implícito en cada autor significativo : el austero aliento de lectura oblicua de la historia de Andrés Rivera, la épica intimista de Saer con su especialísima dificultad y sus exigencias sobre un lector especializado, el análisis de la argentinidad de las obras de teatro de Ricardo Bartís.

6) ¿Podemos hablar de una literatura rioplatense? ¿en qué sentido? (movimientos estéticos comunes, historia cultural compartida, etc.) ¿Cree que ha existido un vínculo mayor en otras épocas?

Tenemos una relación especular pero asimétrica. Como país chico, sabemos más de los argentinos en general que ellos de nosotros. Es ya un lugar común recordar los vínculos uruguayos de Borges tanto como tratar de ubicar geográficamente la Santa María de Onetti. Gardel es un buen ejemplo de las complejidades del vínculo, que pasa por la afirmación o negación de una genealogía y la disputa por una pertenencia.

Hubo grandes vasos comunicantes en las etapas editoriales de los 50 y 60 . Yo trabajé en la Editorial Arca, que distribuía a Jorge Álvarez Editor, una editorial que de modo meteórico armaba antologías que funcionaban como puentes para identificar autores. La Editorial Galerna surgió de esos vínculos de Ángel Rama con Álvarez y su equipo, coeditando rarezas bibliográficas. Angel fue un gran promotor de vínculos, muy consciente de la necesidad de generar asociaciones y puentes.

Ahora bien : si París era el destino manifiesto de todo artista en la primera mitad del siglo, Buenos Aires lo era a nivel regional : Florencio Sánchez y los hermanos Podestá, 
Gardel, se consagraron allá porque la dimensión del espacio cultural y social tenía el abono necesario; Herrera y Reissig tuvo su año porteño; ni qué hablar de Horacio Quiroga, modernista en la selva misionera. El amor mismo : Manuel Ugarte fue, si lo fue, el amor imposible de Delmira Agustini. Cuánto de la distancia y de la elegante imposibilidad habría en ese enamoramiento. La figura del soñador, fundamental en Onetti, se forja en Buenos Aires, en los cuentos anteriores a El Pozo. Onetti es uno de los mejores ejemplos del natural atravesamiento (del mar, que los argentinos llaman río, de la «salida » al mundo, de la soledad empapada de cosmopolitismo) que produce el ir y venir entre ambas orillas. La vida breve no se hubiera escrito sin ese movimiento de desapego y nostalgia.

Como país pequeño (en verdad más despoblado que pequeño) el Uruguay carga con la necesidad constante de establecer su diferencia. El Plan Cóndor de las dictaduras nos arrasó en muchos sentidos.

\section{Sergio Chejfec}

1) ¿Qué le evoca el Río de la Plata ?Qué representa para usted, en su imaginario literario ? Los ríos vienen a representar lo efímero y lo permanente. A lo mejor por el hecho de no tener visible la costa del otro lado, y porque esa otra costa pertenece a otro país, el caso del Río de la Plata deriva en una presencia más insidiosa, abierta y claustrofóbica a la vez. Es un río que dadas sus características lo tiene todo para ser visto, como ha ocurrido desde siempre, como el espacio geográfico que esconde una clave decisiva. Pero no me gusta tomar el río en términos de alegoría. Más bien me gusta considerar las posibilidades literarias de los registros alegóricos.

2) ¿Cuál es su relación biográfica con el país vecino ? ¿con qué frecuencia, a dónde va y por qué motivos viaja al otro lado del Río ?)

Tengo familia en Uruguay, siempre fui por uno $\mathrm{u}$ otro motivo. Mi madre y los suyos son de allí. Durante un tiempo me ilusioné con tomar la ciudadanía uruguaya; lo sentía como la restitución de un equilibrio. Mi padre era el inmigrante real (o por lo menos más real que mi madre, que vino a la Argentina de muy chica). Mi padre vino de Europa del este y nunca habló bien castellano. Por lo tanto, el Uruguay, sobre la Argentina, representaba para mí una idea de origen más vernacular, digamos, que mi propio país. Un lugar primigenio donde gran parte de la familia extendida se había quedado y hacia donde la familia emigrada miraba todo el tiempo como si fuera un espacio de nostalgia y seguro a la vez, que brindaba identidad.

3) ¿Ha escrito en la otra orilla ? ¿Influye la distancia en su escritura ?

Escribí en Uruguay esporádicamente. Nunca estuve en Uruguay más que pocos días.

4) ¿Ha publicado o se ha planteado publicar en el país vecino ? ¿Por qué ?

Nunca estuvo en mis planes, pero me resulta frecuente pensar en eso. Me refiero a vivir allí. En cuanto a publicar, nunca me lo pregunté.

5) ¿Qué autores contemporáneos del país vecino mencionaría y por qué ?

¿Contemporáneos? No sé muy bien cuáles califican. De todos modos no me entero lo suficiente sobre lo que se publica en Uruguay. Puedo mencionar desde Levrero pasando por Mondragón, hasta Circe Maia y Fernanda Trías, y pocos más. 
6) ¿Podemos hablar de una literatura rioplatense? ¿en qué sentido? (movimientos estéticos comunes, historia cultural compartida, etc.) ¿Cree que ha existido un vínculo mayor en otras épocas?

No creo que se pueda hablar de una literatura rioplatense en términos de principio, aunque sí de sentido. La literatura rioplatense puede ser una construcción de lectura, incluida por supuesto la crítica. Respecto del pasado, la verdad es que no sé. Si la pregunta se formula de este modo, obviamente del pasado rescataremos las pruebas de mayor vínculo; pero no nos dice nada de las pruebas de no-vínculo. Encuentro que fuera del siglo XIX, cuando todavía se podría hablar de literaturas que se mueven a través de las fronteras y aún no están reguladas por las instituciones que se ocuparán de ello en el siglo XX, el punto irradiador de mayor ambigüedad y fuerza está dado por Onetti, cuya obra tengo la impresión que actualiza la literatura de Arlt para los mismos escritores argentinos.

Desde otra perspectiva, es claro que Uruguay es desde los comienzos una especie de parque temático de la ficción argentina. La literatura encontró allí una máquina de sentido que si bien no siempre funciona como quisiera el autor que recurre a ella, se ha convertido en un tópico alrededor del cual pueden trazarse puntos de continuidad y unos pocos de ruptura. Muchas veces el Uruguay ha sido algo así como las Sirtes para Julien Gracq, la metáfora moral y social transfigurada en espacio. Pero en el caso de Gracq y varios otros, ese espacio refería más o menos explícitamente a la situación colonial en Francia. Creo que a veces el Uruguay ofrece a la literatura argentina un escenario simbólico sin demasiado trabajo, con resultados cada vez más pobres.

\section{Hernán Ronsino}

1) ¿Qué le evoca el Río de la Plata? ¿Qué representa para usted, en su imaginario literario ?

El Río de la Plata me genera misterio y encierra una combinación extraña entre tragedia y melancolía. El misterio por la ausencia de la otra orilla. La melancolía de un río que se deshace en el mar. Y el rumor de la tragedia política. Para mí el Río de la Plata está tejido por las voces de Onetti, Saer, Conti, Wernicke, por ejemplo.

2) ¿Cuál es su relación biográfica con el país vecino ? ¿con qué frecuencia, a dónde va y por qué motivos viaja al otro lado del Río ?)

No conozco Uruguay. Imagino, mejor, a Uruguay a partir de lo que me cuentan, de lo que leo, de algunas películas que he visto. Dicen que Montevideo es como Buenos Aires hace 30 o 40 años. La imagino a partir del mito, es decir, como una metrópoli contenida. Con aires de provincia, incluso.

3) ¿Ha escrito en la otra orilla ? ¿Influye la distancia en su escritura ?

La distancia es importante en mi escritura. Pero en relación a mi lugar de origen. Un pueblo en la provincia de Buenos Aires. Comencé a escribir para reflexionar de algún modo sobre ese desarraigo. Y además es importante la distancia, tomar cierta perpectiva en relación a los temas que abordo. Siento la necesidad de procesarlos antes de escribirlos.

4) ¿Ha publicado o se ha planteado publicar en el país vecino ? ¿Por qué ?

El próximo año una editorial infantil, Topito ediciones, me publicará un relato ilustrado y hace un par de años la editorial La Propia Cartonera me publicó un cuento. En ambos 
casos me hicieron la propuesta y así surgió la edición. También mis libros están distribuidos en Uruguay pero son libros editados en Argentina.

5) ¿Qué autores contemporáneos del país vecino mencionaría y por qué ?

Si se me permite, incluyo a Levrero como autor contemporáneo. Otros autores : Ercole Lisardi, Horacio Cavallo, Manuel Soriano, Ignacio Alcuri, Dani Umpi. Creo que cada uno de estos autores expresa una línea estética. Y combinados muestran un buen panorama de la diversidad narrativa, de lo que se está escribiendo del otro lado.

6) ¿Podemos hablar de una literatura rioplatense? ¿en qué sentido? (movimientos estéticos comunes, historia cultural compartida, etc.) ¿Cree que ha existido un vínculo mayor en otras épocas?

Me resulta complicado hacer una afirmación semejante. Pero creo que hay un autor al que se lo puede pensar como rioplatense por las temáticas que aborda en sus libros. Y creo que en esos libros puede haber una aproximación a esa idea de literatura rioplatense. Me refiero al argentino, residente desde hace años en Uruguay, Carlos María Domínguez. También, en ese sentido, mencionaría Colonia, la novela del rosarino Juan Martini.

\section{Fernanda Trías}

1) ¿Qué le evoca el Río de la Plata ?Qué representa para usted, en su imaginario literario ?

El río es una presencia tan sólida, tan maciza, en el imaginario de todo montevideano, que casi podríamos decir que no es ni siquiera líquido. En sus Aguafuertes uruguayas, Arlt describe el Río de la Plata como " un gran terreno ». Dice : "A momentos estalla un relámpago y entonces el río se presenta amarillento, siniestro ; parece una verdadera extensión de tierra pisoteada por caballos [...]». Esta descripción me parece maravillosa ; cualquiera que haya cruzado el río en barco hacia Buenos Aires habrá sentido eso en el momento en que no se ve ninguna de las dos orillas. Además, la palabra "siniestro » queda resonando en la frase como el trueno que acompaña a ese relámpago. Montevideo no puede escapar del río, no puede -como Buenos Aires- darse el lujo de « darle la espalda », está fatalmente atado -y de frente- a él, y en ese sentido también es siniestro, como puede ser siniestra cualquier cosa bella e imperecedera.

El Río de la Plata es al mismo tiempo un orgullo y una vergüenza, porque tiene delirios de mar, es un río acomplejado. Y uno aprende desde chico a pararse en la rambla junto a cualquier visitante extranjero y, ante la mueca de desilusión, apurarse a decir : «Es marrón porque es un río : el río más ancho del mundo ».

Yo soy, además, de la generación del « río contaminado ». De eso se habló durante años, del agua contaminada de las playas de Montevideo. El baño no estaba recomendado. En mi familia había una historia de tragedia relacionada con el río. De niño, uno de mis tíos se había bañado en la playa y había contraído una enfermedad llamada " parálisis infantil ». Aquella frase macabra (eso que era mucho más que una " parálisis »-ya de por sí aterradora-, porque era « infantil » y por lo tanto sólo podía ocurrirle a los niños, como el viejo de la bolsa, el cuco o la bruja que comía niños envueltos) quedó para siempre grabada en mi memoria. A veces pensaba en eso, si acaso mi tío habría salido del agua y así sin más, esa cosa, la parálisis, se le habría agarrado a las piernas como una aguaviva gigante. La culpa era del río contaminado por los desechos de todo el mundo, que iban a dar a las playas. De eso se hablaba también, de que el caño salía a la playa y de que los desechos contaminaban las aguas. Mi tío no había quedado totalmente 
paralítico, pero sí había quedado rengo de una pierna y tenía que usar un zapato negro, feo, con una suela muy ancha. Eso se relacionaba de alguna forma con mi abuela, porque en la familia se comentaba que debido a su parálisis, a su discapacidad, la madre lo había consentido hasta convertirlo en un inútil. Eso también quedó grabado en la historia familiar como otras familias graban armas y leones sobre sus escudos.

El río es inseparable de mi imaginario literario -aunque no esté presente, aunque no escriba ni una palabra sobre él- porque es inseparable del imaginario de mi infancia. El Río de la Plata (y sé que es ése y no otro, porque siempre es marrón, un barrizal pisoteado por caballos) aparece a menudo en mis sueños en forma de tsunamis que caen sobre la ciudad o con el peligro de la contaminación. Hace años tuve un sueño en el que todo el planeta estaba contaminado. Había ocurrido un accidente nuclear y para protegerse de la radioactividad teníamos que sumergirnos bajo el agua y esperar hasta que pasara lo peor. Yo me sumergía en el agua turbia del río y al salir veía el terror en los ojos de todos. Luego me daba cuenta : mi piel se había desprendido como harapos y colgaba en gajos, dejándome en carne viva. La contaminación me había alcanzado.

2) ¿Cuál es su relación biográfica con el país vecino ? ¿con qué frecuencia, a dónde va y por qué motivos viaja al otro lado del Río ?)

Viví dos años en Buenos Aires, hasta julio de 2012, cuando gané una beca de New York University para hacer una maestría en escritura creativa y me mudé a Nueva York (donde estoy ahora). De no ser por esa beca, me habría quedado en Buenos Aires. En algún momento pensé que era la única ciudad posible para mí. Pero quién sabe... soy esencialmente nómade; no me aferro a los lugares, siento poca nostalgia. Durante esos dos años, viajé bastante seguido a Montevideo, una vez por mes o cada dos meses, sobre todo para ver a mis padres. Pero siempre me interesó, incluso cuando vivía en Europa, mantener un vínculo con Uruguay. (Me refiero a un vínculo literario, porque el otro es inevitable). Me interesaba mantener el diálogo con mis amigos escritores y estar más o menos al tanto de lo que se escribía y publicaba en Uruguay.

3) ¿Ha escrito en la otra orilla ? ¿Influye la distancia en su escritura?

La distancia está cada vez más presente en mi escritura porque hace ya ocho años que no vivo en Uruguay (me fui a fines de 2004 a Francia, con una beca de la Unesco, y luego me quedé casi cinco años, más uno en Berlín antes de instalarme en Buenos Aires). Las ciudades de adopción tardan en infiltrarse en lo que escribo, o mejor dicho, yo tardo en apropiarme de ellas. Pero finalmente lo hago, y de hecho la mayoría de los cuentos del libro que estoy escribiendo, suceden en esas ciudades; los personajes son extranjeros y se sienten extranjeros. Me interesa la problemática vinculada al ser de otra parte. Y casi siempre el «ser extranjero" habla también de otra cosa, de una incapacidad para pertenecer, para crear lazos; habla de personas que están incómodas en la vida. Vivir lejos de Uruguay también me permitió escribir sobre mi ciudad con más libertad. Para mí, escribir desde lejos tuvo un efecto liberador. Será porque uno se siente en la periferia, uno se olvida de quién es y puede jugar a ser otro.

4) ¿Ha publicado o se ha planteado publicar en el país vecino ? ¿Por qué ?

No publiqué en una editorial argentina, pero al reeditar La azotea (Trilce, 2001; Puntocero, 2010) insistí para que el libro se distribuyera en Buenos Aires; ese fue uno de los motivos principales por los que me interesó apoyar el proyecto venezolanouruguayo de Ulises Milla, que se planteaba -siendo una editorial independientedistribuir en Argentina, Uruguay y Venezuela. Yo necesitaba habitar cabalmente mi nueva ciudad, y no creo que eso sea posible si una parte fundamental de uno está 
ausente. Uno siempre escribe para algunos pocos amigos, esas personas sin las cuales el mundo sería un lugar totalmente hostil, y por eso me parece indispensable que lo que escribo pueda leerse en Uruguay y, ahora también, en Buenos Aires.

5) ¿Qué autores contemporáneos del país vecino mencionaría y por qué ?

Argentina tiene grandes escritores. Podría empezar por los imprescindibles, como Laiseca, Hebe Uhart o Abelardo Castillo, pero no podría llamarlos mis contemporáneos, no tanto por una cuestión de edad (creo que las « generaciones » son mucho más fluidas y complejas que un simple corte etario), sino porque su obra ya está hecha, ha encontrado su voz "definitiva », por decirlo de algún modo. Otros escritores, mayores que yo, aún están produciendo su obra, la están buscando... Entre los más jóvenes, mencionaría a Pablo Farrés, porque tiene un proyecto literario complejo y completo, con un imaginario delirante y un estilo personal denso, que no apuesta a lo que está de moda ; y a Romina Paula (con su novela Agosto) dentro del estilo pop, un estilo que no me interesa particularmente pero que ella logra abordar de manera sobria e inteligente. Un poco mayores, destacaría a Ricardo Strafacce, por la imaginación y el humor delirante de sus libros, que se nutren de la peripecia (sin mencionar su indispensable biografía de Osvaldo Lamborghini) ; y a Osvaldo Baigorria, cronista impecable e intenso, especie de beatnik latino, que mezcla biografía (la del escritor "raro" Néstor Sánchez) y autobiografía de manera muy interesante -como si tejiera una trenza- en su último libro Sobre Sánchez.

6) ¿Podemos hablar de una literatura rioplatense? ¿en qué sentido? (movimientos estéticos comunes, historia cultural compartida, etc.) ¿Cree que ha existido un vínculo mayor en otras épocas?

Me parece imposible no hablar de una literatura rioplatense (yo misma no podría considerarme fuera de ese conjunto), empezando por la tradición común de la literatura gauchesca. El propio Bartolomé Hidalgo, escritor «oriental». Y cabe preguntarse qué habría escrito Borges sin la Banda Oriental. En Borges hay un espacio rioplatense evidente, podríamos decir que en él convergen las dos orillas.

Por otro lado, muchos escritores uruguayos vivieron en Buenos Aires. Onetti y Levrero, por ejemplo. Felisberto Hernández empezó sus giras de conciertos, que duraron años, en las ciudades de la provincia de Buenos Aires. El público y la crítica argentinos han sabido dar espacio a algunos de nuestros escritores incluso antes que nosotros mismos. En ese sentido, Buenos Aires es generosa, aunque también glotona. Cuando algo le gusta, lo siente propio y quiere hacerlo suyo. De ahí ese chiste de Fogwill de que la literatura argentina empezaba en Piriápolis, refiriéndose a Levrero. En la feria de Frankfurt, donde Argentina fue el país invitado, se había mezclado en el stand un libro de Onetti... Pero eso mismo dice mucho, porque es imposible apropiarse de algo si el terreno compartido no es amplio. ¿Acaso podríamos disputarnos a Arguedas o a Lezama Lima? 